\title{
A aprendizagem na educação infantil através do lúdico
}

O presente trabalho analisar a importância do lúdico na educação infantil e sua importância no processo de ensino e aprendizagem. A pesquisa retrata o lúdico e a caracterização do docente, por meio da perspectiva educacional, trazendo conceitos sobre seu papel sob a visão de diferentes autores. Para isso utilizou-se a abordagem qualitativa descritiva, por meio de uma pesquisa bibliográfica. Concluir-se que é preciso que o docente permita que através de jogos e brincadeira as crianças demonstrem suas necessidades e habilidades, e aprendam os mais diversos aspectos do conhecimento, em uma atividade espontânea e imaginaria, enfatizando que jogos e brincadeiras são essenciais para o desenvolvimento da criança. Neste contexto ressalta-se que o ensino é construído pela criança e o docente que cria situações que gera confiança para que a criança construa seu próprio conhecimento. Assim, a criança aprende enquanto brinca e ocorre à descoberta de si mesmo e do outro, além de desenvolver e construir sua realidade, tanto pessoal quanto social, por meio das brincadeiras, registrando sua capacidade social com o auxílio principalmente do docente. Portanto, é preciso que na brincadeira as crianças recriam e estabilizam aquilo que sabem sobre os mais diversos aspectos do conhecimento, porque o brincar é importante e influência o seu desenvolvimento.

Palavras-chave: Brinquedoteca; Ensino infantil; Atividades Lúdicas; Ensino e Aprendizagem; Jogos.

\section{Learning in childhood education through the player}

The present work analyzes the importance of playfulness in early childhood education and its importance in the teaching and learning process. The research portrays the playfulness and the characterization of the teacher, through the educational perspective, bringing concepts about his role under the view of different authors. For this, the qualitative descriptive approach was used, through a bibliographic search. In conclusion, it is necessary for the teacher to allow children to demonstrate their needs and skills through games and play, and learn the most diverse aspects of knowledge, in a spontaneous and imaginary activity, emphasizing that games and play are essential for the development of kid. In this context, it is emphasized that teaching is built by the child and the teacher who creates situations that generate confidence for the child to build their own knowledge. Thus, the child learns while playing and occurs to discover himself and the other, in addition to developing and building his reality, both personal and social, through play, registering his social capacity with the help mainly of the teacher. Therefore, it is necessary that in play children recreate and stabilize what they know about the most diverse aspects of knowledge, because playing is important and influences their development.

Keywords: Toy library; Children's education; Recreational activities; Teaching and learning; Games.

Topic: Pedagogia (Educação Criança e Adolescente)

Reviewed anonymously in the process of blind peer.
Received: 24/10/2020

Approved: 25/01/2021
Francenilde da Silva Feitosa (it)

Universidade Norte do Paraná, Brasil

http://lattes.cnpq.br/6244322090047487

http://orcid.org/0000-0002-3779-6490

francenilde19@gmail.com

Neidiara da Silva Feitosa (iD

Universidade Norte do Paraná, Brasil

http://lattes.cnpq.br/8056138395761376

http://orcid.org/0000-0003-3426-3004

yara.feitosa48@gmail.com

Francisco Rubens Feitosa Júnior (iD)

Universidade Federal do Sul da Bahia, Brasil

http://lattes.cnpq.br/1603533849627421

http://orcid.org/0000-0001-7793-2138

rubensjr21@hotmail.com
Referencing this:

FEITOSA, F. S.; FEITOSA, N. S.; FEITOSA JÚNIOR, F. R.. A aprendizagem na educação infantil através do lúdico. Educationis, v.9, n.1, p.39-45, 2021. DOI: http://doi.org/10.6008/CBPC2318-3047.2021.001.0005 


\section{INTRODUÇÃO}

O lúdico na educação infantil é fundamental para o desenvolvimento das aptidões neurológica dos indivíduos em formação. Pois estabelece vínculos sociais que auxilia a formação das personalidades, desenvolvendo aptidões que facilitará as tomadas de decisões que o indivíduo assumirá na idade adulta (SANTOS, 2012).

$\mathrm{Na}$ atualidade, cada vez mais busca-se na educação infantil a atuação ativa dos docentes na formação das crianças por interações que permeiam a criação de dinâmicas, ou que façam com que elas transformem dados e informações em conhecimentos significativos (OLIVEIRA et al., 2018).

Neste contexto, a tendência da educação atual é ensinar competências e habilidades para que a criança adquira a capacidade de fazer associações com o conteúdo adquirido na escola e consiga solucionar situações do seu cotidiano, assim, o docente deve trabalhar as competências e habilidades a fim de formálas (SOUZA, 2016).

Desse modo, o docente dever evitar trabalhar de forma isolada, dando maior oportunidade as interações que tenha ação interdisciplinar, buscando com que a criança internaliza e reconheça ás experiências de vida pessoal e coletiva. Essa interação permite com que a criança execute brincadeiras e facilite a produção de imagens e signos que são reconhecidos pelo resultado do processo de construção (OLIVEIRA et al., 2018; SILVA, 2011).

Nessa perspectiva, o ensino-aprendizagem com jogos e brincadeiras é uma metodologia que possibilita a criança desenvolver aptidões que a auxilia na descoberta de soluções que facilita as problemáticas que possam surgir em seu cotidiano (PERRENOUD, 2014), sendo também uma metodologia onde os docentes contribuam para o desenvolvimento desses aspectos.

\section{METODOLOGIA}

O presente trabalho utilizou-se da pesquisa qualitativa descritiva para observar e descrever fenômenos através da atuação docência com jogos e brincadeira no ensino das crianças. A escolha desta investigação deve-se ao fato de que o lúdico exerce um papel fundamental no ensino aprendizagem e o docente é um dos responsáveis para mediar esse processo fundamental para o desenvolvimento educacional em sala de aula. Utilizando-se para isso a visão de autores que trabalham principalmente com o lúdico na educação infantil. A análise do delineamento metodológico da pesquisa foi realizada com base em estudos qualitativos, utilizou-se uma planilha para a inserção dos dados, e por último a análise foi realizada de forma descritiva (RODRIGUES, 2007).

\section{DISCUSSÃO TEÓRICA}

Jogos e brincadeiras: o papel do docente de educação infantil

A educação infantil é um direito da criança, e o docente deste segmento construí junto à escola o desenvolvimento cognitivo e psicológico da criança, numa prática sustentada em conhecimento cientifico e 
metodológico (PIMENTA, 2012). A educação abrange a concepção de capacidade de se avaliar as através da consciência de si mesma, dos outros e da sociedade. Sendo uma forma de saber aceitar os outros e oferecer várias ferramentas que possibilita a visão de mundo e de circunstâncias adversas que cada um irá encontrar, assim o ato de educar é preparar para a vida (BRASIL, 2016).

O docente desenvolve então uma prática e uma concepção de infância que permite as condições de criação de um ambiente de ensino coerente, assim como um planejamento com ênfase em atividades lúdicas. Principalmente porque a criança deve adquirir autonomia na solução de problemas e através da liberdade para explorar o mundo ao seu redor (DUARTE, 2013).

O papel do docente infantil é criar ambientes que permitam a aprendizagem prazerosa, saudável, com experiências educativas e sociais variadas. Gerando um espaço que contribua para o ensino e aprendizado através dos jogos e brincadeiras aplicadas em sala de aula (ZABALA et al., 2010).

Entretanto atividades lúdicas não pode ser apenas um instrumento para que a aula seja mais eficiente, a brincadeira e o jogo têm sentido em si, porque o ser humano é lúdico (SANTOS, 1997). Conforme esclarecido por Kishimoto (1994) ao manifestar o imaginário infantil a função pedagógica promove o desenvolvimento integral da criança, nesse sentido, qualquer atividade da escola, através do lúdico é uma forma de interação educativa.

Torna-se essencial que o docente se junte ás crianças no decorrer do jogo ou brincadeiras, o que segundo Maluf (2003), facilita e permite condições para que atividades significativas sejam realizadas, destacando o autor a importância dos alunos trabalharem na sala de aula, individualmente ou em grupo, cabendo também ao docente estabelecer metodologias e condições para desenvolver e facilitar este tipo de trabalho.

Assim as reflexões do docente devem permear por técnicas que permitam aprender o significado de sua prática, através da relação entre teoria e prática, para construção de uma nova teoria de acordo com o seu contexto (SÃO PAULO, 2012). Então o docente mediador não deve propor situações onde a criança seja um ser não participante ou apenas ouvinte, deve-se estar dando oportunidade para construção do conhecimento de forma interacional. Onde a criança tem um ambiente com atividades lúdicas, onde o docente é um mediador no processo de transformação que fará a criança sujeito autônomo e decisivo no contexto inserido (GOMES et al., 2007).

$O$ docente nesse processo se torna fundamental para $\mathrm{O}$ andamento das atividades de ensino diretamente ligada à mediação de conhecimento com as crianças (LUCKESI, 2005). Acredita-se desse modo que a importância das ações planejadas, promove práticas educativas que incentivam as crianças a expressarem suas ideias (SANTOS et al., 2014).

Para Maluf (2003) o docente tem a função de promover ás atividades para o desenvolvimento da criança em sala de aula, além da criação de um local para interação com jogos e uma oficina para construção de novos brinquedos.

Desde a pré-escola é fundamental que a criança apresente a experiência de construir seus brinquedos, pois quando mais participa de atividades lúdicas, o processo de aprendizagem torna-se 
agradável. Para Santos (1997), o ato de brincar é fundamental para que a criança aprenda e se desenvolva, através de práticas usual do docente na realidade educacional (BRASIL, 2016). Dessa forma as atividades lúdicas oportunizam a criança seu conhecimento e sua compreensão de mundo e nas salas de educação infantil.

\section{Estratégias de ensino e aprendizagem}

Os jogos e as brincadeiras sempre estiveram presentes na sociedade, e passaram a ter importância e serem vistos de forma promissora no século XX. Profissionais das ciências sociais através de estudos do lúdico, possibilitaram a existência de melhores metodologias de ensino que ressaltaram que a criança era um ser com necessidades próprias, o que possibilitou uma grande valorização dos jogos e brincadeiras (VYGOTSKY, 1998).

$\mathrm{Na}$ atualidade, o discurso acerca do brincar cada vez mais ganha espaço nas áreas que permeiam a educação, cultural e lazer, pois a educação quase sempre faz com que um jogo seja visto mais pela oportunidade de ensinar, sendo extremamente importante proporcionar a preservação da essência lúdica nas atividades ou brincadeira com função didática (CEBULSKI, 2014).

Ressaltar-se que as crianças aprendem melhor por meio de uma relação afetuosa ao tratar-se de conteúdos e valores, e por meio de jogos e brincadeiras promovem a comunicação efetiva, proporcionando melhor socialização e encorajamento das crianças mais tímidas. E se tratando dos jogos é fundamental a formação de grupos para a busca de soluções coletivas, por meio de cooperação que permita com que as crianças aprendem os principais valores que formam as interações sociais como por exemplo ouvi a opinião do outro (BRASIL, 2017).

O desenvolvimento da personalidade integral da criança sofre influencias benéficas das atividades lúdicas possibilitando o progresso de cada uma de suas funções psicológicas, intelectuais e morais. Dessa forma, a criança encontra-se em constante processo interativo entre, aprender, jogar ou brincar, em uma integração entre o mundo interno e externo, adquirindo a satisfação de determinações interiores, enquanto que as externas beneficiarão a si próprio e também aos outros (VYGOTSKY, 1998).

Os jogos e brincadeiras harmonizam através da substituição de algo ausente no imaginário das crianças, porém, mantendo suas características próprias e desafiando suas dificuldades como criança para satisfazer as necessidades de crescimento e competitividade. Por isso é importante em todos os momentos na sala de aula o uso dessa ferramenta para facilitar a construção do aprendizado (PAVARINO et al., 2004).

Para desenvolver algumas habilidades a criança ao iniciar seu período escolar precisa do lúdico como estratégia para sua formação. Maluf (2003) afirma que a criança é curiosa e está sempre experimentando todas as suas possibilidades e quando é apresentada a uma experiência brincada passa a amadurecer emocionalmente e aprender uma forma de convivência mais rica.

Os jogos e brincadeiras possuem papel no desenvolvimento da criança de forma essencial para a saúde física, emocional e metal (CEBULSKI, 2014). Pois, por meio dos jogos de regras, a criança não desenvolve os aspectos sociais, morais e cognitivas, além do companheirismo, aprendendo a conviver com 
outras crianças e aceitar regras como aguardar sua vez e aceitar resultados.

Todavia brincar é fonte de lazer e fonte de conhecimento, os jogos e brincadeiras desenvolvem a autonomia, e através da escola tem o objetivo de construir seus conhecimentos. Segundo Reis (1971) os jogos coletivos e todas as atividades sociais na escola, tem como premissas possibilitar com que às crianças sejam cada vez mais conscientes das regras e consigam respeitar ao mesmo tempo que visualiza o adulto como apenas um mediador, sem imposições que venha impor ordem, dessa maneira as crianças criam uma organização mútua na solidariedade e num sentimento de justiça diferenciado do adulto.

Esta situação acima, permite observar que ao brincar e jogar em grupo a criança tem autonomia moral e desenvolve o respeito mútuo, sem regras preestabelecidas pelo adulto. Ressaltar-se que os educadores devem analisar as atividades lúdicas com a finalidade de qualificar o relacionamento entre as crianças (ROLIM et al., 2008).

Com isso a brincadeira contempla o princípio norteador das atividades didático - pedagógicas e a escola cumpre seu papel fundamental na vida da criança, estimulando e inserindo possíveis metodologias que contenham uma proposta que vida em sala de aula agindo dessa maneira o aprendizado acontecerá de forma mais completa.

\section{Valorização do brincar e seus resultados sociais}

A criança em um contexto histórico e social a partir de valores significativos e construídos pelos sujeitos que ali vivem incorpora a experiência, porém de forma participa ela traz o seu poder de imaginar, criar, reinventar e produzir cultura (VYGOTSKY, 1998).

Nas escolas brincando a criança melhor supera seus limites, pois uma parte de seus medos e experiências revela as ações e significados que constroem sua forma de pensar, e com isso as brincadeiras gera o processo de referência que pode colocar em evidencia sua vivencia e limites. E com base nas suas experiências o docente reelabora e reinterpreta situações de sua vida cotidiana e insere novos contextos socioculturais que venha trazer benefícios a realidade em sala de aula (BRASIL, 2017).

O ser humano não nasce já sabendo brincar, mas ele aprende a brincar, através de relações que os sujeitos estabelecem com os outros, com a cultura, e constitui um espaço de aprendizagem. Segundo Vygotsky (1987) a brincadeira faz com que a criança desenvolva um comportamento melhor do que o normal de sua idade, pois desenvolve suas percepções através de brinquedos e das atividades em grupo, o que permite que as ações da criança ultrapassem o desenvolvimento já alcançado.

$\mathrm{O}$ ato de participar das brincadeiras aprimora os processos básicos constitutivos das relações sociais como o respeito mútuo a opinião alheia assim como dos modos particulares de brincadeira, como as regras e universos simbólicos que caracterizam e especificam os grupos sociais em que está inserida. Com isso as brincadeiras geram um ambiente de conhecimentos e habilidades no âmbito da linguagem e da cognição (CEBULSKI, 2014).

Em todas as dimensões da existência do ser humano pode expressar o brincar, especialmente na infância, o que ratifica o brincar como fundamental para o desenvolvimento psicossocial. Por intermédio 
disso a criança desenvolve a capacidade de raciocínio, e o entendimento do mundo a sua volta e constrói o seu conhecimento (VYGOTSKY, 2004).

\section{Desafios do educador infantil}

As práticas pedagógicas exigem do docente a capacidade de entende a realidade social onde está inserido e em sala de aula ter condições de revolucionar a educação e a própria sociedade. Para isso é necessário estar apto para enfrentar situações novas e lidar com as novas exigências. Angotti (2002) afirma que o docente possui habilidades e características que deve alicerçar o trabalho escolar, e desenvolver a habilidade de observação com o intuito de melhor avaliar suas ações, além de ser criativo o que faculta condições de aulas participativas.

O educador deve impulsionar e conservar na criança a capacidade de pensamento crítico da realidade, o que contribuirão para sua instrução e educação, assim o docente desenvolve a habilidade de observação continua para conhecer a criança e suas necessidades em aprendizagem e oferece meios para sua formação social e cultural (VYGOTSKY, 1998).

Outra habilidade que deve o docente desenvolve segundo Angotti (2002) é a calma e o respeito pela criança, o que promove a segurança e o desenvolvimento integral da criança, o acreditar no potencial da criança segundo o autor, faz com que ela se torne disciplinada e encontrando no docente uma pessoa confiável. Com isso o docente dominará habilidades e competências e uma pedagogia dinâmica que permitirá transformar a sala de aula num espaço privilegiado de aprendizagem (VYGOTSKY, 2004).

\section{A construção do pensamento da criança}

A criança é um ser social e o contato com o mundo ocasiona a construção do desenvolvimento de determinados conceitos em relação a jogos e brincadeiras, desenvolvendo assim essas aptidões em sala de aula que tanto a ajudará na condição de resolução de problemas cotidianos. Maluf (2003) afirma que na brincadeira oportuniza vivenciar as regras impostas e também a alternativa e modificar essas regras para atender uma demanda, o que não é uma mera aceitação, mas de um processo de construção.

Os jogos necessitam ter um planejamento e serem direcionados para atender uma determinada necessidade que as crianças em sala de aula venham a precisar, assim, devem-se inserir os jogos na sala de aula, já consciente do importante da ludicidade no contexto escolar, visto que ela proporciona uma maior interação entre o estudante e o aprendizado.

Uma criança que pensa ativamente inclui qualidades e discernimento da sua realidade e autonomia em situações que exigem um pensamento lógico em pouco espaço de tempo. Neste contexto ressalta-se que o ensino é construído pela criança e o docente cria situações que gera confiança para que a criança mesma construa seu próprio conhecimento.

\section{CONCLUSÕES}

A ludicidade possui influencia na saúde mental e no desenvolvimento do ser humano, sendo 
fundamental a atenção dos pais e educadores para propiciar o direito da criança para o exercício da relação afetiva com o mundo, com as pessoas e com os objetos através de jogos e brincadeiras.

Assim, a criança aprende enquanto brinca e ocorre à descoberta de si mesmo e do outro, além de desenvolve e constrói sua realidade, tanto pessoal quanto social, por meio das brincadeiras, registrando suas capacidades sociais e dos recursos afetivos e emocionais com o auxílio principalmente do docente. Portanto, é preciso que na brincadeira as crianças recriam e estabilizam aquilo que sabem sobre os mais diversos aspectos do conhecimento, porque o brincar é importante e influência o seu desenvolvimento.

\section{REFERÊNCIAS}

ANGOTTI, M.. O trabalho docente na Pré-escola: revistando teorias, descatinando práticas. São Paulo: Pioneira, 2002

BRASIL. Diretriz Curricular da Educação Infantil da AMARP. Videira: Própria, 2016.

BRASIL. Lei n. 13.415: Altera as Lei no 9.394/1996. Lei de Diretrizes e Bases da Educação. Brasília: DOU, 2017.

BRASIL. Ministério da Educação e do Desporto Secretaria de Educação Fundamental Referencial Curricular Nacional Para a Educação infanta da Educação e do Desporto. Brasília: Secretaria de Educação Fundamental, 1998.

CEBULSKI, M. C.. Um Diálogo entre Vygotsky e o Sistema Teórico da Afetividade Ampliada: o teatro na educação básica e o desenvolvimento soco emocional humano. Tese (Doutorado em Educação) - Universidade Federal do Paraná Curitiba, 2014.

DUARTE, J. R. G.. Formação continuada de rede: um estudo de caso da formação de professores no Município de Lagoa Santa. Dissertação (Mestrado em Educação) - Universidade Federal de Minas Gerais, Belo Horizonte, 2013.

GOMES, R. S.; MACEDO, S. H.. Cálculo estequiométrico: o terror das aulas de química. Vértices, v.9, p.149-160, 2007.

KISHIMOTO, T. M.. O jogo e a educação infantil. São Paulo: Pioneira, 1994.

LUCKESI, C. C.. Avaliação da aprendizagem escolar. 16 ed. São Paulo: Cortez, 2005.

MALUF, A. C. M.. Brincar: prazer e aprendizado. 3 ed. Petrópolis: Vozes, 2003.

OLIVEIRA, J. A. S.; SILVA, N. C.. O lúdico como ferramenta de aprendizagem na educação infantil. Revista Saber Acadêmico, v.25, 2018.

PAVARINO, M. G.; DEL PRETTE, A.; DEL PRETTE, Z. A. P.. O desenvolvimento da empatia como prevenção da agressividade na infância. Revista PSICO, v.36, n.2, p.127134, 2004

PERRENOUD, P.. Construindo competências desde a escola. Porto Alegre: Artes Médicas Sul, 2014.

PIMENTA, S. G.. Estágio e docência. 7 ed. São Paulo: Cortez, 2012.
REIS, B. E.. A aprendizagem sob um enfoque cognitivista. Rio de Janeiro: Propil, 1971.

RODRIGUES, W. C.. Metodologia Científica. Paracambi: FAETEC/IST, 2007.

ROLIM, A. A. M.; GUERRA, S. S. F.; TASSIGNY, M. M.. Uma leitura de Vigotsky sobre o brincar na aprendizagem e no desenvolvimento infantil. Revista Humanidades, Fortaleza, v.23, n.2, p.170-180, 2008.

SANTOS, D.; PRIMI, R.. Desenvolvimento socioemocional e aprendizado escolar: uma proposta de mensuração para apoiar políticas públicas. Educação para o Século XXI. São Paulo: Instituto Ayrton Senna, 2014.

SANTOS, J. S.. O lúdico na educação infantil. In: FIPED FÓRUM INTERNACIONAL DE PEDAGOGIA, 9. Anais. Campina Grande: Realize, 2012

SANTOS, S. M. P.. O lúdico na formação do Educador. 6 ed. Petrópolis: Vozes, 1997.

SÃO PAULO. Currículo do Estado de São Paulo: Ciências da natureza e suas tecnologias. São Paulo: Secretaria da educação, 2012.

SILVA, F. F.. A vivência lúdica na prática da educação infantil: dificuldades e possibilidades expressas no corpo da professora. Dissertação (Mestrado em Educação) Universidade Federal de São João Del Rei, São João Del-Rei, 2011.

SOUZA, E. V. R.. Alfabetização e letramento na Educação Infantil: um estudo de caso em uma Instituição de Educação Infantil no Município de Lagoa Santa. Dissertação (Mestrado em Educação) - Universidade Federal de Minas Gerais, Belo Horizonte, 2016.

VYGOTSKY, L. S.. Psicologia pedagógica. 2 ed. São Paulo: Martins Fontes, 2004.

VYGOTSKY, L. S.. Pensamento e linguagem. 2 ed. São Paulo: Martins Fontes, 1998.

VYGOTSKY, L. S.. A formação social da mente. São Paulo: Martins Fontes, 1987

ZABALA, A.; ARNAU, L.. Como aprender e ensinar competências. Artmed: Porto Alegre, 2010.

A CBPC - Companhia Brasileira de Produção Científica (CNPJ: 11.221.422/0001-03) detém os direitos materiais desta publicação. Os direitos referem-se à publicação do trabalho em qualquer parte do mundo, incluindo os direitos às renovações, expansões e disseminações da contribuiç̃o, bem como outros direitos subsidiários. Todos os trabalhos publicados eletronicamente poderão posteriormente ser publicados em coletâneas impressas sob coordenação da Sustenere Publishing da Companhia Brasileira de Produção Científica e seus parceiros autorizados. Os (as) autores (as) preservam os direitos autorais, mas não têm permissão para a publicação da contribuição em outro meio, impresso ou digital, em português ou em tradução. 